\title{
SWINE LUNGS EXPRESSING HUMAN COMPLEMENT-REGULATORY PROTEINS ARE PROTECTED AGAINST ACUTE PULMONARY DYSFUNCTION IN A HUMAN PLASMA PERFUSION MODEL
}

C. William Daggett, $\mathrm{MD}^{\mathrm{a}}$

Mark Yeatman, FRCS ${ }^{a}$

Andrew J. Lodge, MD

Edward P. Chen, MD $^{a}$

Peter Van Trigt, $\mathrm{MD}^{\mathrm{a}}$

Guerard W. Byrne, PhD

John S. Logan, $\mathrm{PhD}^{\mathrm{c}}$

Jeffery H. Lawson, MD

Jeffrey L. Platt, MD ${ }^{a, b}$

R. Duane Davis, MD ${ }^{a}$
Pulmonary transplantation is currently limited by the number of suitable cadaver donor lungs. For this reason, pulmonary xenotransplantation is currently being investigated. Objective: Our goal was to assess the role of complement in pulmonary xenograft dysfunction. Methods: The pulmonary function of swine expressing human decay accelerating factor and human CD59 $(n=6)$ was compared with that of the lungs from nontransgenic (control) swine $(n=6)$ during perfusion with human plasma. Results: After 2 hours of perfusion, the pulmonary vascular resistance was $1624 \pm 408$ dynes $\cdot \mathrm{sec} \cdot \mathrm{cm}^{-5}$ in control lungs and $908 \pm 68$ dynes $\cdot \mathrm{sec} \cdot \mathrm{cm}^{-5}$ in transgenic lungs $(p<0.05)$. Control lungs had a venous oxygen tension of $271 \pm 23 \mathrm{~mm} \mathrm{Hg}$ with a ratio of venous oxygen tension to inspired oxygen fraction of $452 \pm 38$ at 2 hours of perfusion; transgenic lungs had a venous oxygen tension of $398 \pm 11 \mathrm{~mm} \mathrm{Hg}$ and a ratio of venous oxygen tension to inspired oxygen fraction of $663 \pm 18(p<0.05)$. Control lungs showed a decrease of $79.8 \% \pm 3.7 \%$ in static pulmonary compliance by 2 hours, versus a $12.0 \% \pm 8.1 \%$ decrease by the transgenic lungs $(p<0.05)$. The control lungs also developed $561.7 \pm 196.2 \mathrm{ml}$ of airway edema over 2 hours, in contrast to $6.5 \pm 1.7 \mathrm{ml}$ in transgenic lungs $(p<0.05)$. Conclusion: Lungs from swine expressing human decay accelerating factor and human CD59 functioned better than nontransgenic swine lungs when perfused with human plasma. These results suggest that complement activation is involved in producing acute pulmonary xenograft dysfunction and demonstrate that lungs from swine expressing human decay accelerating factor and human CD59 are protected against pulmonary injury when perfused with human plasma. (J Thorac Cardiovasc Surg 1997;113:390-8)
Since the first clinical lung transplantation by S James Hardy in $1963,{ }^{1}$ improvements in surgical technique and advances in immunosuppression have

From the Departments of Surgery, ${ }^{\text {a }}$ Pediatrics, and Immunology, Medical Science Research Building, Duke University Medical Center, Durham, N.C., and from Nextran, ${ }^{\circ}$ Princeton, N.J.

Supported by the National Institutes of Health grants HL50985 and HL52297.

Read at the Seventy-sixth Annual Meeting of The American Association for Thoracic Surgery, San Diego, Calif., April 28-May 1, 1996.

Received for publication May 6, 1996; revisions requested July 3, 1996; revisions received Sept. 4, 1996; accepted for publication Sept. 26, 1996.

Address for reprints: R. Duane Davis, MD, Assistant Professor of Surgery, Director of Cardiopulmonary Transplantation, Duke University Medical Center, DUMC 3864, Durham, NC 27710.

Copyright (C) 1997 by Mosby-Year Book, Inc.

$0022-5223 / 97 \$ 5.00+0 \quad \mathbf{1 2 / 6 / 7 8 3 8 1}$ made this procedure the most rapidly growing area in solid organ transplantation. ${ }^{2}$ As is the case for other organs, donor availability continues to be a limiting factor in performing these procedures. ${ }^{3}$ Because only $10 \%$ to $20 \%$ of cadaveric donors have lungs suitable for pulmonary transplantation, ${ }^{4}$ and because no acceptable long-term mechanical replacement is currently available for the lung, the use of animals for lung donors is being considered. Swine were chosen as a potential lung donor source because of their domestication, anatomic similarities to human beings, short gestational period, and rapid growth.

Complement-mediated hyperacute rejection presents a major barrier to the successful transplantation of vascularized xenografts. ${ }^{5}$ This process is associated with endothelial damage, coagulation, cellular and platelet adherence, and accelerated capillary leak. ${ }^{6}$ Although hyperacute rejection has 


\section{The Isolated Working Lung Preparation}

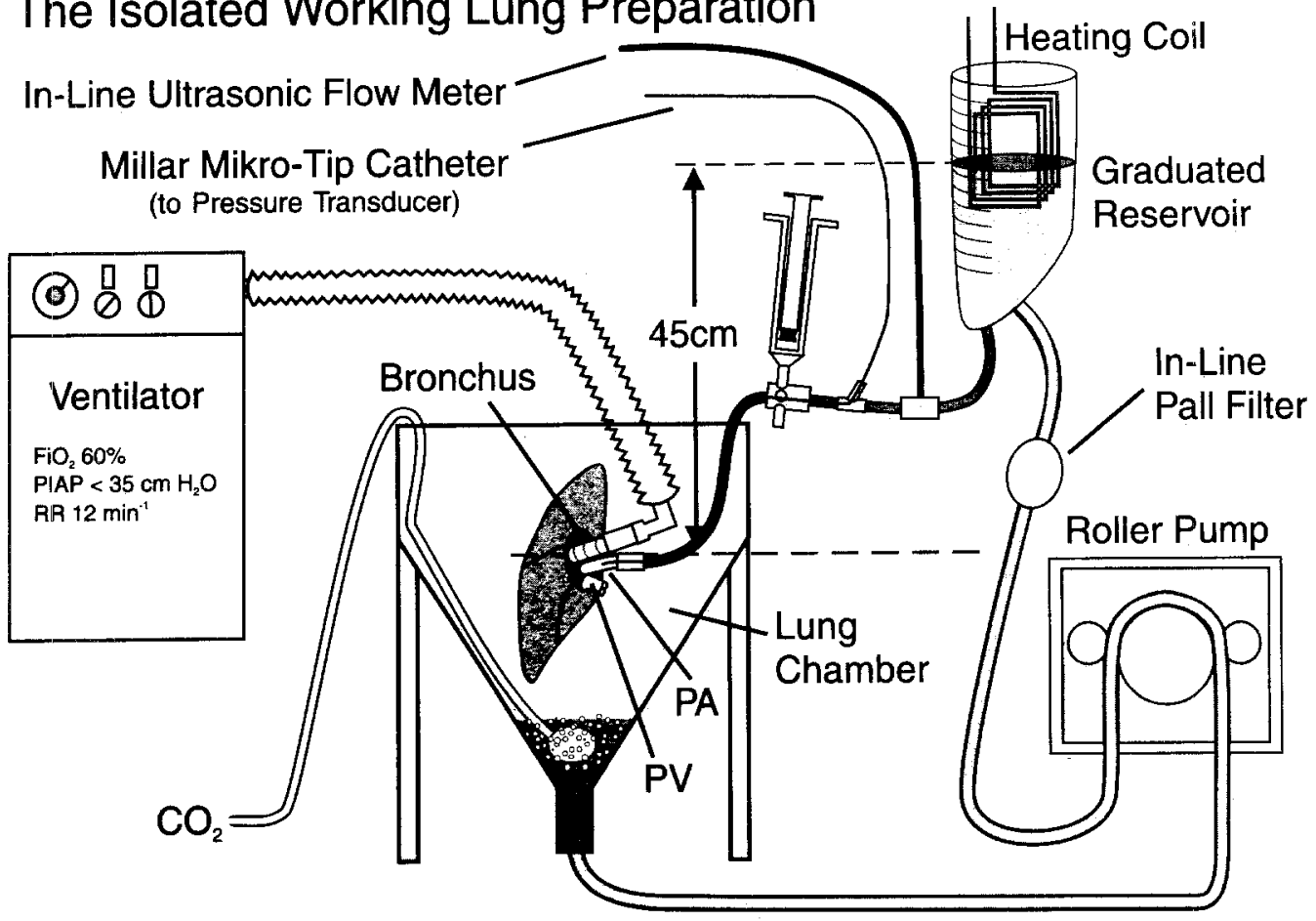

Fig. 1. Diagram of isolated working lung apparatus. Plasma enters the pulmonary artery under gravity from the upper reservoir at a height of $45 \mathrm{~cm}$ above the pulmonary artery. Plasma is allowed to drain into the lower reservoir, where carbon dioxide is added by a diffuser. The roller pump recirculates the plasma from the lung chamber to the upper reservoir, where it is warmed to $37^{\circ} \mathrm{C}$ by a heat exchanger. The lung is ventilated with $60 \%$ oxygen at a rate of 12 breaths/min. $P A$, Pulmonary artery; $P V$, pulmonary vein; $R R$, respiratory rate; $P I A P$, peak inspiratory airway pressure.

been studied extensively in heart and kidney xenografts, the role of complement in pulmonary xenograft rejection is a subject of controversy. Investigation of pulmonary xenograft rejection has been hindered by the lack of a good model. Very limited pulmonary flow during prior attempts to perfuse swine lungs with human blood products has prevented the examination of the mechanisms of rejection in these models. ${ }^{7}$ Furthermore, no good immunohistologic markers have been found in association with pulmonary xenograft injury. In contrast to other vascularized xenografts, swine-to-primate pulmonary xenografts do not show the deposition of activated complement products on their endothelium despite functional failure and the appearance of rejection on gross examination. ${ }^{8}$

Because the complement-regulatory proteins of swine are incompatible with the human complement system, swine xenografts are excessively susceptible to complement-mediated injury. One approach to overcome this problem is to express human comple- ment-regulatory proteins in the donor animal. ${ }^{9,} 10$ Transgenic swine have been created that constitutively express the human complement-regulatory proteins, decay accelerating factor (hDAF) and CD59 (hCD59). DAF accelerates the decay of C3 convertase, an enzyme responsible for the amplification of both the classical and alternative complement pathways. CD59 acts by preventing assembly of the membrane attack complex. The expression of $\mathrm{hDAF}$ and $\mathrm{hCD} 59$ in these animals has been shown to be effective in preventing hyperacute rejection, as demonstrated by the prolongation of cardiac xenograft survival in the swine-to-primate model. ${ }^{10}$

To investigate the ability of transgenic swine lungs to resist the acute pulmonary injury seen when swine lungs are exposed to human plasma, we studied the pulmonary hemodynamics, aerodynamics, gas exchange, and development of edema of nontransgenic and $\mathrm{hDAF} / \mathrm{hCD} 59$ transgenic swine lungs perfused with human plasma in an isolated working lung model. 


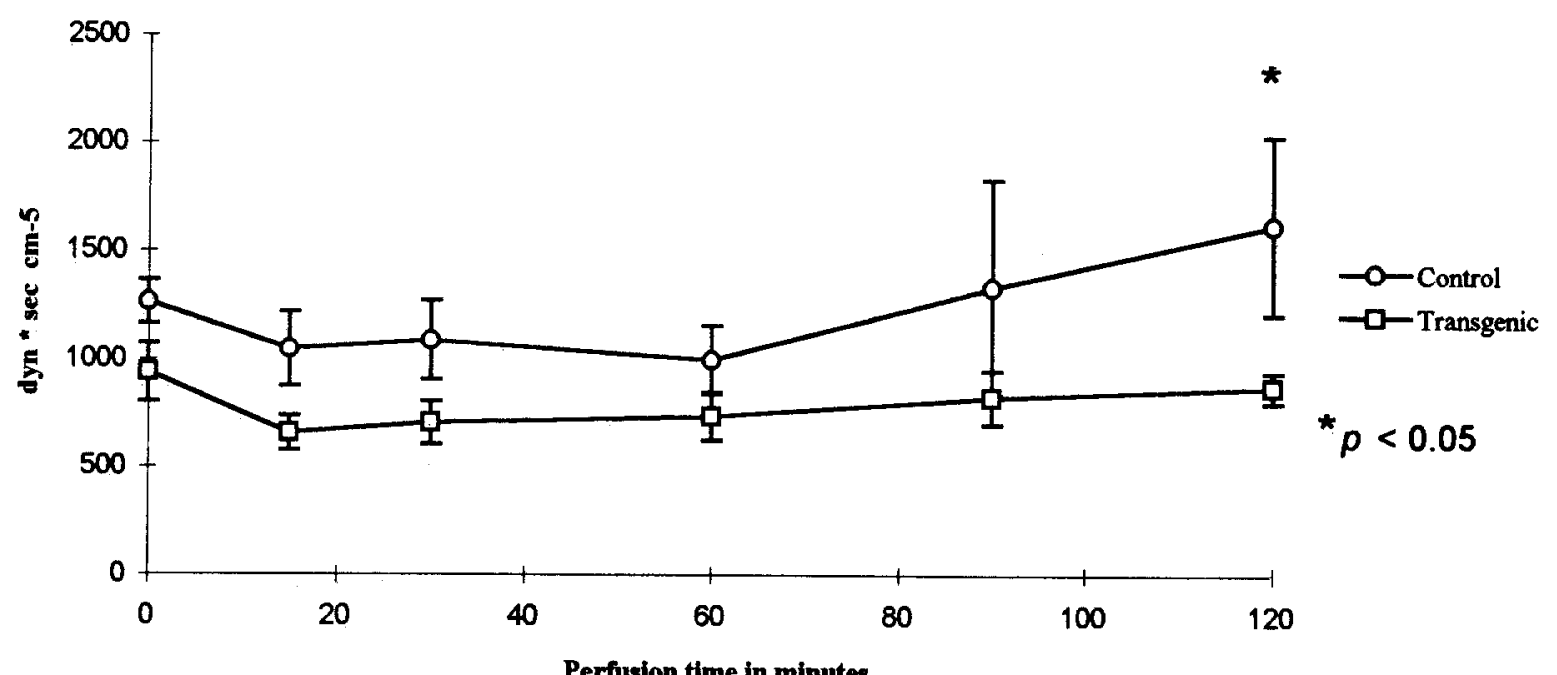

Fig. 2. PVR of isolated swine lungs perfused with human plasma. ${ }^{*} p<0.05$ (analysis of variance), transgenic versus control over time.

\section{Materials and methods}

Swine. Adult swine (60 to $75 \mathrm{~kg}$ ) transgenic for hDAF and hCD59 were supplied by Nextran, Princeton, New Jersey. The $\beta$-actin-CD59 transgene contains a chick $\beta$-actin promoter, controlling expression of complementary DNA hCD59. The $\mathrm{H} 2 \mathrm{~K}^{\mathrm{b}}$-DAF transgene contains a mouse $\mathrm{H}_{2} \mathrm{~K}^{\mathrm{b}}$ promoter, which regulates expression of complementary DNA hDAF. These swine have demonstrated the expression of hDAF and hCD59 messenger ribonucleic acid in the lung and other tissues. ${ }^{11}$ Functional expression of human complement-regulatory proteins was confirmed by a three- to fivefold resistance of peripheral blood lymphocytes to human complement-mediated lysis. ${ }^{11}$ All nontransgenic (60 to $75 \mathrm{~kg}$ ) adult swine were obtained from Walnut Hill Farms, Hillsborough, North Carolina.

Lung harvesting. All animals received humane care in compliance with the "Guide for the Care and Use of Laboratory Animals" published by the National Institutes of Health (NIH publication No. 86-23, revised 1985). Animals were anesthetized with intramuscular administration of ketamine hydrochloride $(20 \mathrm{mg} / \mathrm{kg})$ and intravenous fentanyl $(5 \mu \mathrm{g} / \mathrm{kg})$. Animals were intubated and ventilated with $100 \%$ oxygen at a rate of 10 breaths $/ \mathrm{min}$ with a tidal volume of $12 \mathrm{ml} / \mathrm{kg}$. Arterial pressure and blood gases were monitored through cannulation of the right femoral artery. A median sternotomy and thymectomy were performed and the pericardium was opened. The azygos and hemiazygos veins were ligated and the inferior and superior venae cavae were loosely encircled with umbilical tape. Prostaglandin $\mathrm{E}_{1}(50 \mu \mathrm{g} / \mathrm{kg})$ was injected directly into the pulmonary artery and heparin was administered intravenously $(500 \mathrm{U} / \mathrm{kg}) 10$ minutes before harvest. The venae cavae were ligated and the left and right atria were incised to allow for venting during the preservation process. Euro-Collins solution $(25 \mathrm{ml} / \mathrm{kg})$ was administered into the pulmonary artery from a height of $30 \mathrm{~cm}$. The inferior pulmonary ligaments were sharply divided and the trachea was divided with a stapling device. The heart and lungs were then removed en bloc and immersed in cold $\left(4^{\circ} \mathrm{C}\right)$ saline solution. Lungs were separated and cannulas were placed into the main bronchus and pulmonary artery and secured with suture ligatures. The total ischemic time in both groups was consistently less than 35 minutes.

Isolated lung apparatus. The isolated lung apparatus was constructed as shown in Fig. 1. Lungs were ventilated with an adult volume-controlled ventilator (Bennett Respiration Products, Inc., Santa Monica, Calif.) with $60 \%$ oxygen at a rate of 10 breaths $/ \mathrm{min}$, adjusting the tidal volume to maintain the peak airway pressure at $35 \mathrm{~cm}$ $\mathrm{H}_{2} \mathrm{O}$. Perfusion was achieved by delivering the plasma to the pulmonary artery from a reservoir at a height of $45 \mathrm{~cm}$ above the pulmonary artery. The perfusate was collected into a lower reservoir and recirculated through a $20 \mu \mathrm{m}$ filter (Pall Biomedical, Inc., Fajardo, Puerto Rico) to the upper reservoir by a roller pump (Sarns Inc., Ann Arbor, Mich.). The temperature of the perfusate was maintained at $37^{\circ} \mathrm{C}$ by a heat exchanger (Medtronic Cardiopulmonary, Anaheim, Calif.) inside the upper reservoir.

Preparation of human plasma used for perfusion. The perfusate for each lung consisted of 5 pooled units (175 to $225 \mathrm{ml}$ ) of type $\mathrm{O}$ rhesus + fresh human plasma (American Red Cross, Durham, N.C.). The plasma was thawed to $30^{\circ} \mathrm{C}$ in a water bath and heparinized with heparin sodium $(16 \mathrm{U} / \mathrm{ml})$ before pooling. The pooled plasma was combined with a $40 \%$ volume of lactated Ringer's solution. Sodium bicarbonate, magnesium sulfate, and calcium chloride were added to the solution for a final composition of $\mathrm{pH} 7.4$, bicarbonate $25 \mathrm{mmol} / \mathrm{L}$, potassium $4 \mathrm{mmol} / \mathrm{L}$, calcium ${ }^{++} 1.2 \mathrm{mmol} / \mathrm{L}$, magnesium 1.0 $\mathrm{mmol} / \mathrm{L}$, and sodium $140 \mathrm{mmol} / \mathrm{L}$. The plasma solution was briefly circulated before perfusion, being warmed to $37^{\circ} \mathrm{C}$, and carbon dioxide was directly diffused into the upper reservoir maintaining the carbon dioxide tension between 35 and $45 \mathrm{~mm} \mathrm{Hg}$. 


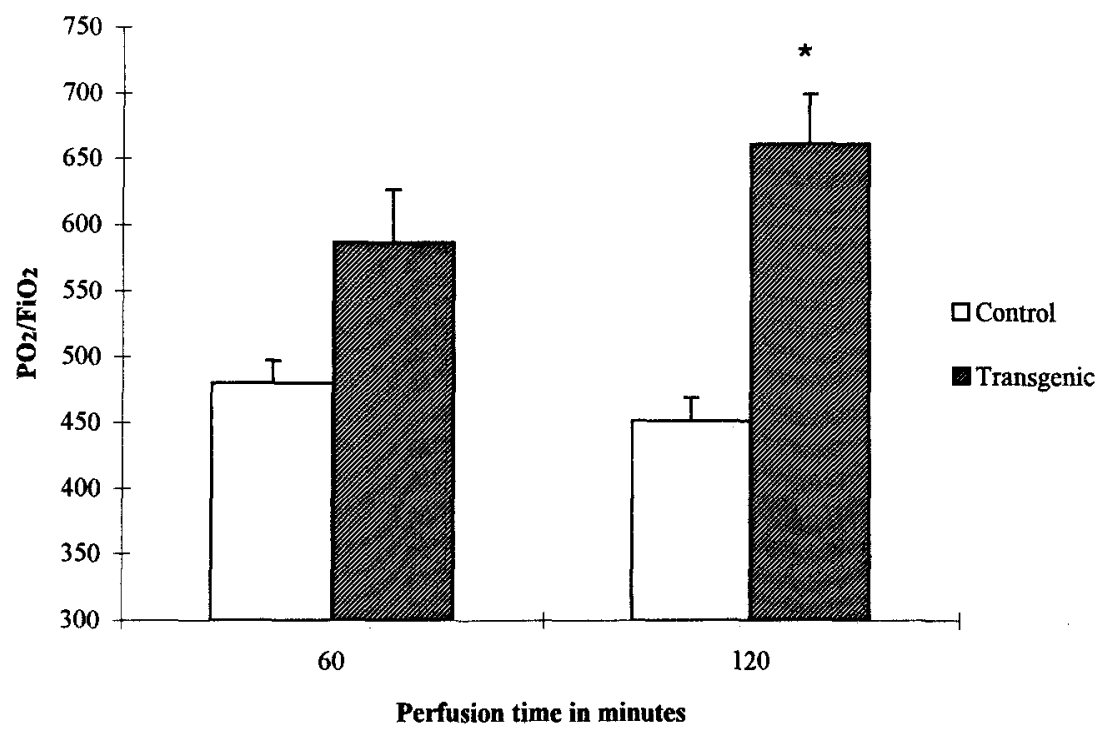

Fig. 3. Ratio of oxygen tension $(\mathrm{mm} \mathrm{Hg})$ in pulmonary venous sample $\left(\mathrm{Po}_{2}\right)$ divided by the fraction of inspired oxygen $\left(\mathrm{FiO}_{2}\right) .{ }^{*} p<0.05$ ( $t$ test), transgenic versus control at 120 minutes of perfusion with human plasma.

Data acquisition. Pulmonary artery flow was measured with an ultrasonic in-line flowmeter (Transonics Systems, Inc., Ithaca, N.Y.) and pulmonary artery pressure was determined with a Millar Mikro-Tip micromanometer (Millar Instruments, Inc., Houston, Tex.) positioned in the proximal pulmonary artery. Blood gases were measured with a Gem-Stat blood gas analyzer (Mallinckrodt Sensor Systems, Inc., Ann Arbor, Mich.) from pulmonary venous samples. End-expiratory volume and pressure were measured with an adult volume-controlled ventilator (Bennett Respiration Products, Inc., Santa Monica, Calif.). Edema was measured by the volume of fluid accumulation in the airway during the procedure.

Immunohistochemistry. Lung biopsy specimens were taken before perfusion. Inflated lung specimens were snap-frozen in precooled isopentane and stored at $-80^{\circ} \mathrm{C}$. Frozen tissue sections ( $4 \mu \mathrm{m}$ thick) were prepared in a Leica cryostat (Leica, Heidelberg, Germany). The sections were air-dried, fixed with acetone, and washed with phosphate-buffered saline solution. Each section was then incubated with a fluorescein isothiocyanate-conjugated primary reagent (rabbit antibody to hDAF, rabbit antibody to hCD59, or the GS-I-B4 lectin [Vector Laboratories, Burlingame, Calif.], which has specific binding to $\alpha-1,3$ galactose). Tissue sections were washed with phosphate-buffered saline solution after incubations and mounted with $p$-phenylenediamine/glycerol solution. Sections were evaluated with a Leitz DMRB epifluorescence microscope (Leica) and photographed.

Statistical analysis. Data (given as the mean \pm standard error of the mean) were analyzed by two-way analysis of variance with SigmaStat statistical analysis software (Jandel Scientific, San Rafael, Calif.) and considered significant at the $p<0.05$ level.

\section{Results}

Pulmonary vascular resistance. Control lungs $(n=6)$ displayed a higher pulmonary vascular resistance (PVR) over time than transgenic lungs (Fig. 2) $(p<0.05)$. At the end of 2 hours, control lungs had a pulmonary flow of $1102 \pm 117 \mathrm{ml} / \mathrm{min}$ and a PVR of $1624 \pm 408$ dynes $\cdot \mathrm{sec} \cdot \mathrm{cm}^{-5}$, whereas transgenic lungs $(n=6)$ had a pulmonary flow of $1388 \pm 46 \mathrm{ml} / \mathrm{min}$ and a PVR of $908 \pm 68$ dynes $\cdot \mathrm{sec} \cdot \mathrm{cm}^{-5}$.

Gas exchange. The gas exchange of the lungs was assessed by calculating the ratio of pulmonary venous oxygen partial pressures $\left(\mathrm{Pvo}_{2}, \mathrm{~mm} \mathrm{Hg}\right)$ to inspired oxygen $\left(\mathrm{Fio}_{2}\right)$. Transgenic lungs displayed better oxygenation than control lungs after 2 hours of perfusion. After 1 hour of perfusion, control lungs hạd a $\mathrm{Pvo}_{2}$ of $288 \pm 24 \mathrm{~mm} \mathrm{Hg}$ with a $\mathrm{PvO}_{2} / \mathrm{FiO}_{2}$ of $480 \pm 40$; transgenic lungs had a $\mathrm{Pvo}_{2}$ of $352 \pm 10 \mathrm{~mm} \mathrm{Hg}$ and $\mathrm{a}_{\mathrm{Pvo}_{2}} / \mathrm{Fio}_{2}$ of $587 \pm 17$ $(p=0.05)$. After 2 hours of perfusion, control lungs had a $\mathrm{Pvo}_{2}$ of $271 \pm 23 \mathrm{~mm} \mathrm{Hg}$ with a $\mathrm{Pvo}_{2} / \mathrm{Fio}_{2}$ of $452 \pm 38$ and transgenic lungs, a $\mathrm{Pvo}_{2}$ of $398 \pm 11$ $\mathrm{mm} \mathrm{Hg}$ and $\mathrm{a} \mathrm{Pvo}_{2} / \mathrm{Fio}_{2}$ of $663 \pm 18(p<0.05)$ (Fig. 3).

Compliance. Transgenic lungs had significantly greater retained compliance over time than control lungs. Control swine lungs began to lose compliance within the first minute of perfusion with human 


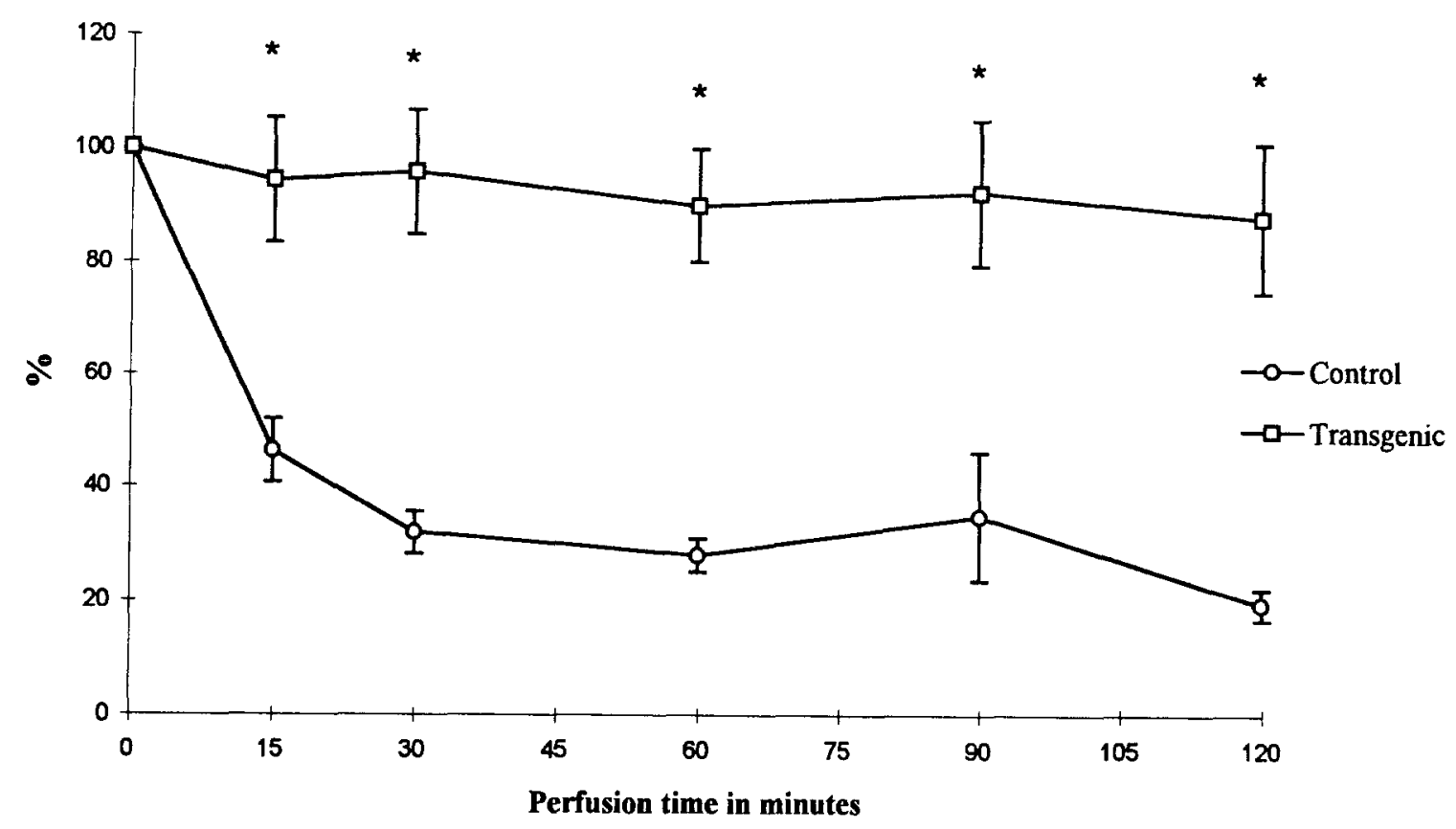

Fig. 4. Static pulmonary compliance of isolated swine lungs perfused with human plasma (shown as percentages of initial values). ${ }^{*} p<0.05$ ( $t$ test), transgenic versus control at individual time points.

plasma (Fig. 4). The decline in compliance appeared to correlate with the development of pulmonary edema. After 120 minutes of perfusion, the control lungs had a $79.8 \% \pm 3.7 \%$ reduction in static pulmonary compliance. In contrast, there was little change in the compliance of $\mathrm{hDAF} / \mathrm{hCD} 59$ lungs during the 2 hours of perfusion, with only a $12.0 \% \pm$ $8.1 \%$ reduction in static pulmonary compliance by the end of 2 hours of perfusion $(p<0.05)$.

Pulmonary edema. Edema consistently developed within minutes of perfusion in control lungs. After 2 hours of perfusion of control lungs, edema formation progressed to the extent $(561.7 \pm 196.2$ $\mathrm{ml})$ that the reservoir volume was significantly depleted, thus limiting the study period to 2 hours. Transgenic lungs displayed an impressive protection from the development of edema during the 2-hour study period, with $6.5 \pm 1.7 \mathrm{ml}$ of airway fluid accumulation $(p<0.05)$ (Fig. 5).

Immunohistochemistry. Biopsy specimens of lung tissue were taken before perfusion and stained for the presence of hDAF and hCD59. Both hDAF and hCD59 were found to be present on the pulmonary endothelium in transgenic swine lungs and absent in nontransgenic lungs (Fig. 6). Immunofluorescent staining for GS-I-B4 lectin was not different between transgenic and nontransgenic lungs.

\section{Discussion}

Investigation of pulmonary xenoperfusion began with the early development of cardiopulmonary bypass, during which canine lungs were used to oxygenate human blood. ${ }^{12}$ In these studies, the rapid development of edema and high PVR limited pulmonary function to 15 to 20 minutes. ${ }^{12,13}$ In 1968 , Bryant, Eiseman, and Avery ${ }^{13}$ reported similar results in swine lungs perfused with human blood, achieving less than $10 \%$ of adult human pulmonary blood flow. Rapid development of edema, loss of blood flow, and subsequent deterioration of gas exchange has been noted in each of these reports and in other studies of pulmonary xenoperfusion. ${ }^{7,12-14}$ Although these phenomena have been consistently reported, the mechanisms causing these processes have not been elucidated.

The development of airway edema and decreased gas exchange in control swine lungs in this study is consistent with prior reports of pulmonary heterologous perfusion. The protection of swine lungs expressing human complement-regulatory proteins from human plasma implies that complement plays an important role in pulmonary xenograft rejection. The transgenic swine used in this study have demonstrated expression of hDAF and hCD59 in the lung, as well as in other tissues. ${ }^{11}$ The hDAF and 


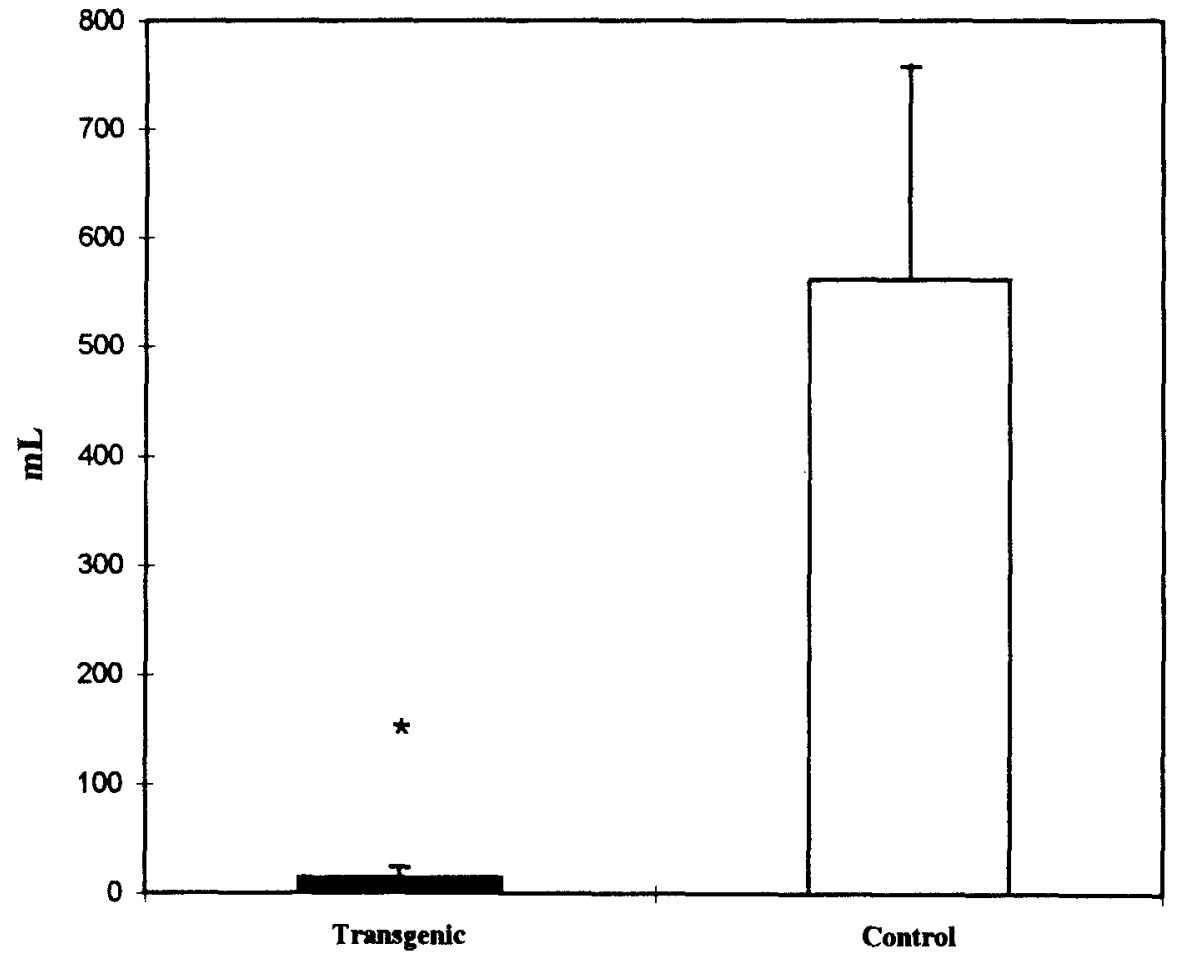

Fig. 5. Total amount of edema formation after 120 minutes of perfusion with human plasma. ${ }^{*} p<0.05$ ( $t$ test), transgenic versus control at 120 minutes of perfusion with human plasma.

hCD59 proteins are functional, as measured by protection of peripheral swine lymphocytes from human complement lysis. ${ }^{11}$ And hearts from these same transgenic swine have been shown to overcome complement-mediated hyperacute rejection when transplanted into baboons. ${ }^{10}$

The significance of complement-regulatory proteins in preventing hyperacute rejection rests in the ability to inhibit species-specific complement activation. These membrane-bound proteins are relatively restrictive, such that an organ transplanted into a recipient of a phylogenetically disparate species does not have the ability to regulate the activation of complement in the recipient. ${ }^{15}$ Inasmuch as recipient complement is highly activated by a xenograft and the xenograft does not have the ability to regulate this activation, complement activation continues uninhibited. This results in the generation and deposition of terminal complement complexes and leads to hyperacute rejection. A promising new development in the field of xenotransplantation has been the creation of animals expressing human complement-regulatory proteins.

The isolated lung model used in this study facilitates accurate measurements of hemodynamic and aerodynamic parameters and has several features that distinguish it from an in vivo pulmonary xenograft. One element, in particular, is the use of plasma as opposed to whole blood. Plasma was chosen as a perfusate to examine the humoral immune response free from the effects of platelets and cell-mediated processes. The complex interactions between humoral and cellular elements in whole blood, which may contribute to the loss of pulmonary xenograft function, do not take place in this model. ${ }^{16,17}$ For example, the increase in PVR in this study, while significant, is considerably less than previously reported when whole blood was used as a perfusate. ${ }^{7,13,14}$ Platelets in the perfusate may contribute to the development of increased PVR through the release of thromboxane $A_{2}$ from activated platelets. In addition, neutrophils activated by complement are known to contribute to pulmonary injury through several different mechanisms, including the generation of oxygen-derived free radicals. ${ }^{18}$ The absence of neutrophils in this model removes this potentially relevant process. Furthermore, extracorporeal circulation has been shown to cause pulmonary injury in association with homologous complement activation through the alternative path- 

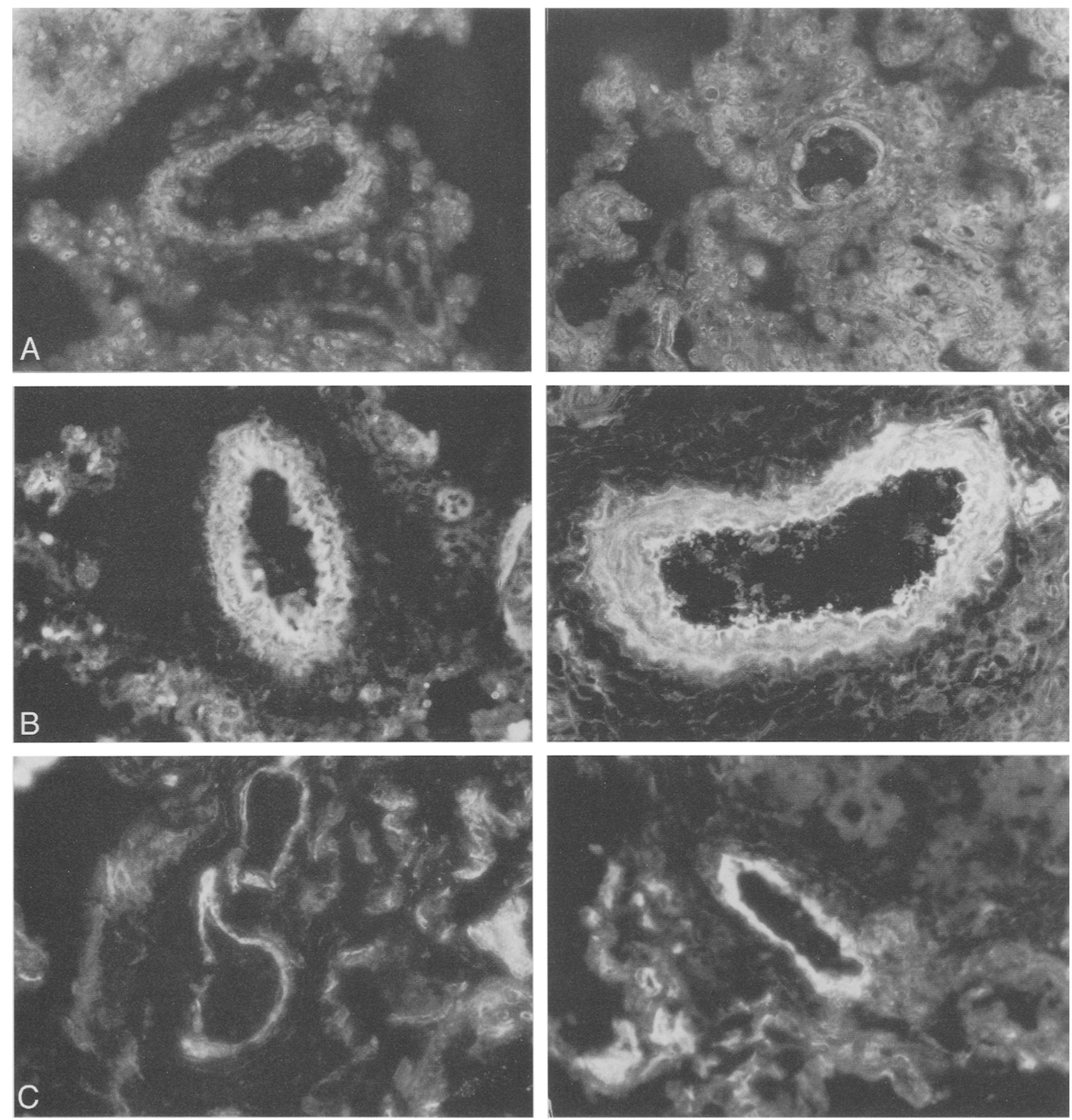

Fig. 6. Immunofluorescent micrographs of nontransgenic (A) and transgenic swine lung tissue (B) and human lung tissue (C) stained with fluorescent rabbit antibody to hDAF (left) and hCD59 (right) before perfusion with human plasma.

way such as occurs with cardiopulmonary bypass. ${ }^{19}$ Although the length of cardiopulmonary bypass is associated with increasing complement activation and pulmonary injury, ${ }^{20}$ the degree of pulmonary injury and loss of function associated with extracorporeal circulation is relatively minor compared with the profound lung injury manifest by the immediate development of massive pulmonary edema and pulmonary vasoconstriction observed in heterologously perfused lungs. ${ }^{7,12-14}$

Although the mechanisms of injury in heterologously perfused lungs have not been defined, they 
differ from those described in other vascularized xenografts. ${ }^{6}$ Hyperacute rejection of heart and kidney xenografts is caused by the binding of xenoreactive antibodies to antigens expressed on the endothelial surface of the xenograft. The most important antigen is believed to be $\alpha-1,3$ galactose. Complement activation through the classical pathway has been shown to be an integral component in the process of hyperacute rejection of heart and kidney xenografts. ${ }^{5,6}$ After hyperacute rejection of the heart or kidney, complement deposition is present in abundance on the endothelial surface. ${ }^{6}$ Although complement activation occurred during perfusion of both transgenic and nontransgenic lungs in the present study, as measured by a three- to fivefold increase in the levels of C3a-desArg, endothelial complement deposition is minimal (data not shown), as has been previously reported by Kaplon and colleagues ${ }^{8}$ in orthotopic swine-to-primate pulmonary xenografts.

A potential limitation of this study is the lack of demonstrable difference in complement activation between the transgenic and nontransgenic groups. However, the swine used for the study were not inbred, they were of similar age and weight, and they expressed the $\alpha-1,3$ galactose antigen similarly. The only observable difference between transgenic and nontransgenic swine in this study was the presence of the hDA.F and hCD59 in the transgenic swine, which were associated with profound differences in pulmonary function after heterologous perfusion.

In models of complement inhibition using the soluble complement receptor, $\mathrm{SCR} 1$, or depletion of complement with cobra venom factor, hyperacute cardiac rejection is prevented and prolongation of xenograft survival has been achieved for up to 25 days. $^{21,22}$ In contrast, in a study by Pierson and associates, ${ }^{7}$ neither cobra venom factor nor heat treatment was effective in preventing pulmonary rejection when swine lungs were perfused with human blood. However, the protection of swine lungs expressing human complement-regulatory proteins from damage by human plasma in the current study implies that complement is involved in this process. This discrepancy may be related to the particular methods of complement depletion. Because cobra venom factor and heat treatment of whole blood may increase the release of vasoactive substances and stimulate coagulation, it may be that the method used to deplete complement actually contributed to the profound pulmonary hypertension observed in that study.
In conclusion, lungs from swine expressing the human complement-regulatory proteins, hDAF and hCD59, were consistently protected against increased PVR, decreased ability to transport oxygen, loss of compliance, and development of edema when perfused with human plasma. This study implies that complement is involved in pulmonary xenograft injury and suggests that transgenic swine may lead to a useful source for expanding the pulmonary donor pool.

\section{REFERENCES}

1. Hardy JD, Webb WR, Dalton ML. Lung homotransplantation in man. JAMA 1963;186:1065-74.

2. Cooper JD, Pearson FG, Patterson GA. Technique of successful lung transplantation in humans. J Thorac Cardiovasc Surg 1987;93:173-81.

3. Owens CE, Evans RW, Acher NL. Estimates of organ specific donor availability for the United States. Transplant Proc 1993;25:1541-42.

4. Sundaresan S, Trachiotis GD, Aoe M, et al. Donor lung procurement: assessment and operative technique. Ann Thorac Surg 1993;56:1409-13.

5. Platt JL, Fischel RJ, Matas AJ, Reif SA, Bolman RM, Bach FH. Immunopathology of hyperacute xenograft rejection in a swine-to-primate model. Transplantation 1991;52:214-20.

6. Platt JL, Bach FH. The barrier to xenotransplantation. Transplantation 1991;52:937-47.

7. Pierson R III, Kaspar-Konig W, Tew DN, Young VK, Bradley PC, White DJ, et al. Profound pulmonary hypertension characteristic of pig lung rejection by human blood is mediated by xenoreactive antibody independent of complement. Transplant Proc 1995;27:274.

8. Kaplon RJ, Platt JL, Kwiatkowski PA, Edwards NM, Xu H, Shah AS, et al. Absence of hyperacute rejection in pig-toprimate orthotopic pulmonary xenografts. Transplantation 1995;59:410-6.

9. McCurry KR, Kooyman DL, Diamond LE, Byrne JW, Martin MJ, Logan JS, et al. Human complement regulatory proteins in transgenic animals regulate complement activation in xenoperfused organs. Transplant Proc 1995;27:317-8.

10. McCurry KD, Kooyman DL, Alvarado CW, Cotterell A, Martin M, Logan $\mathbf{J}$, et al. Human complement regulatory proteins protect swine-to-primate cardiac xenografts from humoral injury. Nature Med 1995;1:423-7.

11. Byrne GW, McCurry KR, Martin MJ, McClellan SM, Platt JL, Logan JS. Transgenic pigs expressing human CD59 and DAF produce an intrinsic barrier to complement mediated damage. Transplantation. In press.

12. Campbell $\mathrm{G}$, Crisp N, Brown E. Total cardiac bypass in humans utilizing a pump and heterologous lung oxygenator (dog lungs). Surgery 1956:40:364-71.

13. Bryant L, Eiseman B, Avery M. Studies of the porcine lung as an oxygenator for human blood. J Thorac Cardiovasc Surg 1968;55:255-63.

14. Katsuyuki K, Aust JC, Wax SD, Webb WR. Hemodynamic and functional changes in xenogenic, perfused, isolated lungs. J Thorac Cardiovasc Surg 1976;72:115-8.

15. Dalmasso AP. The complement system in xenotransplantation. Immunopharmacology 1992;24:149-60. 
16. Rosenberg JC, Hawkins E, Rector F. Mechanisms of immunological injury during antibody-mediated hyperacute rejection of renal heterografts. Transplantation 1971;11:151-7.

17. Rosenberg JC, Broersma RJ, Bullemer G. Relationship of platelets, blood coagulation, and fibrinolysis to hyperacute rejection of renal xenografts. Transplantation 1969;8:152-61.

18. Johnson KJ, Ward PA. Role of oxygen metabolites in immune complex injury of lung. J Immunol 1981;81:2365-9.

19. Craddock PR, Fehr J, Brigham KL, Kronenberb RS, Jacob HS. Complement and leukocyte-mediated pulmonary dysfunction in hemodialysis. N Engl J Med 1977;296:769-74.

20. Kirklin JK, Westaby S, Blackstone EH, Kirklin JW, Chenowith $\mathrm{DE}$, Pacifico AD. Complement and the damaging effects of cardiopulmonary bypass. J Thorac Cardiovasc Surg 1983; 86:845 -57.

21. Pruitt SK, Baldwin R III, Marsh H Jr, Lin SS, Yeh CJ, Bollinger R. The effect of soluble complement receptor type 1 on hyperacute xenograft rejection. Transplantation 1991; 52:868-73.

22. Leventhal JR, Dalmasso AP, Cromwell JW, Platt JL, Manivel CJ, Bolman R III, et al. Prolongation of cardiac xenograft survival by depletion of complement. Transplantation 1993; 55:857-66.

\section{Discussion}

Dr. Richard N. Pierson III (Nashville, Tenn.). This study demonstrates conclusively that complement is in fact involved in the hyperacute rejection process of pig lungs by human blood and is an important contribution to our understanding of that process. My questions are three. Have you looked for evidence of endothelial cell activation in the context of these plasma-perfused pig lungs, which would be important then in other processes that might occur later in the hyperacute rejection process? Second, do you have any information on perfusion of these lungs with whole blood as opposed to cell-free plasma? Third, I noticed that you had a Pall filter in your perfusion circuit. Why did you think that was an important thing to have?

Dr. Daggett. Thank you, Dr. Pierson. We did not evaluate endothelial cell activation in this study but are currently evaluating such using electron microscopy. In answer to your second question, the results obtained, transplanting these transgenic swine lungs orthotopically into baboons, demonstrated that they were protected from acute pulmonary dysfunction. To answer your third question about the Pall filter, we thought that the chance of embolizing those lungs with fibrin or other cellular debris was an important factor in determining the PVR and could contribute to the decline in pulmonary function. Therefore, to prevent this from occurring, we chose to have a filter in the circuit.

Dr. Dao Minh Nguyen (Houston, Tex.). Have you have expanded your experiment beyond 120 minutes? If so, what happened to the transgenic lung?

Dr. Daggett. In this model and in other ex vivo models, there tends to be a decline in function of an organ over time. Even when swine lungs are perfused with autologous plasma, after approximately $2 \frac{1 / 2}{2}$ hours of perfusion the model begins to deteriorate. The limiting factor in this study, however, was pulmonary edema formation in the control lungs. After 120 minutes, the pulmonary edema caused sufficient loss in the reservoir volume and limited this study to 120 minutes.

Dr. Larry R. Kaiser (Philadelphia, Pa.). Have you evaluated these lungs histologically, and can you describe your findings?

Dr. Daggett. We have looked at the histology and immunopathology in these lungs. An interesting feature of pulmonary xenografts, as opposed to the heart and the kidneys, is that they do not display either the xenoreactive antibodies or products of complement activation on their endothelial surface. One possible explanation for this is that the endothelial surface of the lungs is approximately 97 times greater than that of the heart. An immunofluorescent stain would be expected to be distributed over 97 times the area, which may not show up as much. The other histologic features of pulmonary xenograft rejection in our models seemed to include several things: the massive infiltration of leukocytes, the formation of platelet and fibrin plugs, and the disruption of alveoli in the lungs. These processes were all found to be considerably less when we used transgenic hCD59 and hDAF lungs in this model.

Dr. Keith Naunheim (St. Louis, Mo.). Dr. Daggett, have you considered doing bronchoscopy with bronchoalveolar lavage to look at the number of macrophages you can harvest and the cytokine profile?

Dr. Daggett. We have not investigated that. 